\title{
The needs of children whose mothers have HIV infection
}

Jacqueline Mok, Sarah Cooper

\begin{abstract}
Aim-To ascertain the psychological, social, and educational needs of children born to mothers with HIV infection.

Methods-Review of case records of 120 children and 86 mothers.

Results-The cohort of 120 children were born to 92 women, and followed up for a median duration of 48 months (mean (SD) 51.1 (34.1), range 0.3-132). Sixteen children were infected with HIV, 15 were of indeterminate status, and 89 uninfected. Eighty one children $(68 \%)$ were cared for by their birth mother, of whom $52 \%$ were single women and $23(38 \%$ of 61$)$ known to have symptomatic HIV disease. Twenty five mothers of 32 children had died; the child's mean (SD) age at maternal death was 66.9 months (37.7) (range 4-128). Compared with uninfected children, more infected children knew of their mother's diagnosis $(31 \% v 5 \%)$ and mothers were also more likely to disclose their own illness to educational authorities $(77 \% v$ $13 \%)$. A larger proportion of infected children had special educational needs $(69 \% v$ $13 \%)$. Only 33 children (28\%) were known not to be receiving any support from the voluntary or statutory agencies.

Conclusion-The results highlight the multiple needs of children living with maternal HIV infection, which require dedicated resources and commitment from health, education, and social work agencies and the voluntary sector. We propose the model of chronic illness as the standard of care for these children. (Arch Dis Child 1997;77:483-487)
\end{abstract}

Keywords: maternal HIV; AIDS orphans; special needs

Infection with HIV was recognised in children in 1982, and research has concentrated mainly on early diagnosis, risks, and factors influencing vertical transmission, medical care, the clinical spectrum, and natural history. ${ }^{1-4}$ Treatment prospects for infected children are promising, ${ }^{56}$ and HIV infection is now considered a chronic illness with demands on already scarce resources. In the developed world, the rate of transmission of HIV from an infected mother to her child is estimated at $15 \%,{ }^{1}$ and is likely to fall with the introduction of antiretroviral treatment given to women in the antenatal period. ${ }^{7}$ With about one in eight children likely to acquire HIV from their infected mother, there are thus more uninfected than infected children. The wider implications of HIV in the family have received little attention until recently, ${ }^{8-11}$ but to date, studies have not documented children's needs beyond estimating the numbers requiring alternative care.

The Children Act of 1989 defined 'children in need' as those who are disabled, or who are unlikely to achieve or maintain a reasonable standard of health or development without the provision of local authority services. ${ }^{12}$ This definition is open to interpretation by the providers of services, especially when resources are limited. Although the Children (Scotland) Act of 1995 included children affected by illness and disability in the family as those also in need', no obligation exists for local authorities to be proactive in identifying the needs of any child except those who are disabled. ${ }^{13}$

Although many children affected by HIV come from families characterised by isolation, deprivation, and dysfunction, they are by no means an homogeneous group. In the UK, a significant proportion are under the age of 10 and belong to a racial or ethnic minority or are the children of a parent, or parents, who misuse drugs. In Edinburgh and the Lothians, it is estimated that there are between $300-500$ children affected by HIV in the family because of one or both parents being infected with the virus. $^{101415}$ The predominant route of infection for the adults was needle sharing drug misuse, and the families have a history of poor relationships with the statutory services. Many families are known to the paediatric service at the City Hospital in Edinburgh, however, because the children were recruited into a study evaluating the risk of HIV transmission from mother to child, and have been followed up prospectively since $1985 .{ }^{16}$ The contact has been maintained for the majority of families through community based services even when medical follow up has ceased. This study examines the social, emotional, and educational characteristics of children (those infected and those not infected with the virus) born to women with HIV, and seeks to document some of the needs which have arisen.

\section{Subjects and methods}

All children born between 1 January 1984 and 31 December 1996 to women with HIV infection, and referred to the paediatric service at the City Hospital were included in the study. Edinburgh is one of 10 centres from seven European countries recruiting children into the European Collaborative Study. ${ }^{1}$ A standard protocol is used for every child. Where the woman is identified in the antenatal period, the infant is seen within a week of birth and every 
three months until the infection status of the child is established. If the child is referred after the newborn period, the same protocol is used, and information on their health and development is obtained retrospectively from neonatal and child health surveillance records. HIV infection diagnosis is based on the detection of virus (culture or polymerase chain reaction) in two separate blood samples or the persistence of antibody beyond 18 months of age. A child is presumed uninfected if two separate blood samples show no laboratory evidence of HIV infection (negative for HIV antibody, antigen, and virus), and has no clinical signs or symptoms suggestive of HIV infection. ${ }^{17}$ An affected child is one who lives in a household where one or both parents have HIV infection. The vast majority of these children are not infected with HIV, but are seriously affected by the stigma and social and medical consequences of parental illness. ${ }^{1015}$

Infected children were seen as clinically indicated (at least every three months) while uninfected children were seen at least annually. At each visit, information was collected on a standard questionnaire on the clinical, developmental, and sociodemographic circumstances. A history was taken and the child examined for symptoms and signs suggestive of HIV disease. Developmental screening was done using the Denver developmental screening test. Length, weight, and head circumference were documented. Information was also collected on the nature of child care (birth parent, foster carer, or adoptive parent), change in child care arrangements, and maternal health. Additional information on educational status and aspects of care were obtained from community child health records. Data entry was performed using Microsoft Access database.

Demographic information on the mothers was collected at enrolment into the European Collaborative Study. This included country of birth, marital status, age at leaving full time education, and risk activity for acquiring HIV. Maternal clinical data were gained from a separate database kept at the City Hospital, and were only available for women who attended for follow up at the adult HIV clinic. Health of the mothers was coded using the Centers for Disease Control (CDC) classification for HIV infection. ${ }^{18}$

Statistical analysis was performed using $\chi^{2}$ tests, using Yates's correction, and also $\chi^{2}$ tests for trend where appropriate.

\section{Results}

THE MOTHERS

There were 92 women, of whom 90 were white and $86(94 \%)$ attended the adult HIV clinic. Forty six women also had hepatitis $C$ virus infection. Their mean (SD) age at delivery of the child was 25.6 years (4.7) (range 17-35). The majority of women (81) had acquired HIV and hepatitis $\mathrm{C}$ virus through injecting drugs. Twenty five mothers (27\%) had died, 14 from HIV related illnesses, five from non-HIV medical causes (of whom three had liver failure), five from overdoses, and one committed suicide. At the time of maternal death, the 32 affected children in the cohort were aged from 4-128 months (mean 66.9; SD 37.7). Six family units had been affected by mother and child deaths.

Information on their health was available on 61 of the surviving mothers. While asymptomatic HIV infection (CDC stage II and III ) was documented in 38 women, 23 (38\%) had stage IV disease with debilitating physical and mental illnesses.

\section{THE CHILDREN}

From 1 January 1984 to 31 December 1996, 120 children were referred to the paediatric HIV service. The median length of follow up was 48 months (mean 51.1; SD 34.1; range 0.3-132). Five were withdrawn from follow up after contact in the newborn period, but information on health, developmental, and educational progress, as well as care arrangements were available from community child health records. No concerns had been documented about their health or development, and for the purposes of further analysis, these children are presumed uninfected. Of the remaining 115 children, 16 were infected with HIV, three had hepatitis $\mathrm{C}$ virus infection, 86 were uninfected, and 10 who were less than 18 months old were of indeterminate status. So far, none of the indeterminate children has shown any laboratory or clinical evidence of HIV infection, and so are presumed uninfected for comparison with the infected children. No child had dual infection with HIV and hepatitis $\mathrm{C}$ virus.

The cohort comprised 92 family units, of which 52 had two or more children in the study. Fifty five children were firstborn and 43 children had no siblings. A total of 156 siblings (range 0-5) were known, resulting in at least 224 children affected by maternal HIV infection. Teenage and non-dependent children of the women were unlikely to be known to the clinic. The cohort known to the paediatric service represents between $45-75 \%$ of all affected children in Edinburgh and the Lothians. Ten children have died, of whom three were uninfected (sudden infant death, aspiration pneumonia, gastroenteritis). All seven deaths in infected children were from an HIV related illness. All the children with hepatitis $\mathrm{C}$ virus infection were alive and asymptomatic. They are considered as 'HIV uninfected', and are not considered a separate group in the analysis of results, as there were no medical, educational, or social consequences of their hepatitis $C$ virus infection.

\section{CARE OF THE CHILDREN}

Eighty five children $(71 \%)$ were cared for by their birth parent(s) when last seen, while nine lived with relatives. Twenty six children $(22 \%)$ were in long term alternative care-nine with foster carers and 17 with adoptive families. Of the children with birth parents, only 33 were in two parent families. There were 52 lone parent families-48 single mothers and four single fathers. For 46 children (38\% of cohort: nine infected, 37 uninfected) who had ever been in 
Table 1 Care of the children, according to the child's HIV status

\begin{tabular}{lllr}
\hline Type of care & $\begin{array}{l}\text { No (\%) } \\
\text { HIV infected }\end{array}$ & $\begin{array}{l}\text { No (\%) } \\
\text { HIV uninfected }\end{array}$ & Total \\
\hline $\begin{array}{lllr}\text { Within family } \\
\text { Birth parent(s) }\end{array}$ & $9(56)$ & $76(73)$ & 85 \\
$\begin{array}{l}\text { Other relative } \\
1(6)\end{array}$ & $8(8)$ & 9 \\
Outside carers & & & \\
$\begin{array}{l}\text { Foster care (long } \\
\text { term) }\end{array}$ & $1(6)$ & $8(8)$ & 9 \\
$\quad$ Adopted & $5(31)$ & $12(11)$ & 17 \\
Total & 16 & 104 & 120 \\
\hline
\end{tabular}

Comparing the child's HIV status to type of care received (care within the family to outside carer), $\chi^{2}$ with Yates's correction $=$ $1.76, \mathrm{p}=0.19$.

care, the numbers of households lived in by them in addition to the family home, ranged from one to four. The median (SD) age at first placement in care was 26 months (27.5) (range birth to 115 months). No differences were found in the frequency of carers, when the HIV status of the children were examined $\left(\chi^{2}\right.$ test for trend $=0.14, p=0.7)$. It was more likely, however, for infected children to be cared for outside the family, although the result did not reach statistical significance (table 1 ). No child lived in an institution. Reasons for being in alternative care were known for 34 children; the reason was child protection in 24 cases and maternal illness or death in 10 cases.

\section{EDUCATION}

Ninety nine children (84\%) attended an educational setting, of whom 13 were infected. Table 2 outlines the attainments of the cohort, and shows that infected children were more likely to have special educational needs. Of the nine infected children receiving extra educational support, all were receiving it for learning difficulties and/or physical disabilities in the later stages of their illness. None was in a special school. In contrast, the 11 uninfected children who received special education did so because of behavioural problems (nine children) and learning difficulties (two children). Of the children with behavioural disorders, two were in special schools - one child was taught at home, having been excluded from school for disruptive and aggressive behaviour. The infected child's diagnosis was made known to education staff in all but one case. Parental HIV illness was more likely to be disclosed to the child as well as the school where the child was infected (table 3).

SUPPORT FOR FAMILIES

Thirty three children (28\%) and their families received no support from either statutory or voluntary organisations. Although a greater

Table 2 Educational attainments of the children

\begin{tabular}{llll}
\hline Educational status & $\begin{array}{l}\text { No (\%) } \\
\text { HIV infected } \\
(n=13)\end{array}$ & $\begin{array}{l}\text { No (\%) } \\
\text { HIV uninfected } \\
(n=86)\end{array}$ & Statistical analysis \\
\hline Age appropriate grade & $10(77)$ & $81(94)$ & $\begin{array}{l}\chi^{2} \text { Yates's correction }= \\
11.08 \mathrm{p}<0.001\end{array}$ \\
$\begin{array}{l}\text { Receiving special } \\
\text { educational support }\end{array}$ & $9(69)$ & $11(13)$ & $\begin{array}{c}\chi^{2} \text { Yates's correction }= \\
18.67 \mathrm{p}<0.0001\end{array}$ \\
\hline
\end{tabular}

Some children received extra support within their appropriate grade at school.
Table 3 Disclosure of parent's diagnosis (where known)

\begin{tabular}{llll}
\hline $\begin{array}{l}\text { Diagnosis } \\
\text { disclosed }\end{array}$ & $\begin{array}{l}\text { HIV } \\
\text { infected } \\
(\%)\end{array}$ & $\begin{array}{l}\text { HIV } \\
\text { uninfected } \\
(\%)\end{array}$ & Statistical analysis \\
\hline To child & $5 / 16(31)$ & $5 / 101(5)$ & $\begin{array}{l}\chi^{2} \text { Yates's correction }= \\
11.04 \mathrm{p}<0.001\end{array}$ \\
To school & $10 / 13(77)$ & $9 / 67(13)$ & $\begin{array}{l}\chi^{2} \text { Yates's correction }= \\
20.86 \mathrm{p}<0.0001\end{array}$
\end{tabular}

Figures represent number where diagnosis disclosed/number of children where information available.

proportion of infected children (88\%) compared with uninfected children $(70 \%)$ were in contact with voluntary or statutory organisations, the result did not reach statistical significance. Voluntary and statutory agencies were more likely to be in contact with the family if the parental HIV illness had been disclosed to the child.

\section{Discussion}

This study highlights the needs of uninfected as well as infected children of women who are infected with HIV, the majority of whom abused drugs. The difficulties in identifying and following up women who are drug abusers are well known. Yet about half of all affected children in Edinburgh and the Lothians were known to the paediatric HIV service at the City Hospital. This is partly due to the family clinic, set up in 1985, where children and their parent(s) could attend for medical evaluation at the same time. Despite the family clinic, follow up was still erratic until community based venues were used, which often included the family's home. ${ }^{19}$ Working with agencies in the community also improved contact and continuity of care, and resulted in comprehensive knowledge of the children's health, development, education, and welfare long after attendance at the paediatric clinic stopped. We propose that the chronic childhood illness model, involving professionals from different agencies in the hospital and community, be used as the standard of care for children infected with, and affected by, HIV. For clinicians who look after a small number of these children, care could be shared with a tertiary centre.

Part of this cohort was the subject of an earlier report which examined the independent effects of maternal drug misuse and HIV. ${ }^{20} \mathrm{Up}$ to the age of 3 years, neither maternal HIV infection nor reported drug use during pregnancy exerted major influences on child health or development. Maternal HIV and drug use, however, exerted independent negative influences on child care. Compared with community controls, children whose mothers misused drugs in pregnancy or who had HIV infection were less likely to be living with birth parents at 10 months of age (odds ratio 0.3 ). This present study extends the follow up to a median of 4 years, and confirms the vulnerability of the children, as only $71 \%$ of the cohort remained with both parents when last seen. This concurs with the overall figure of $70 \%$ of children in 10 European centres who had been cared for by a birth parent at an average age of 39 months. ${ }^{11}$ Whereas in the European Collaborative Study, 
the extended family provided care for $57 \%$ of children who had ever lived away from their parent; this situation was less likely to prevail with the children from Edinburgh. The culture of drug abuse in young people resulted in loss of family support, either through alienation of their parents or because of an unwillingness to disclose the reasons for seeking help. As a result, only nine children were in the care of another family member (five with grandparents, four with an aunt). Drug abuse was a significant factor for maternal death as well as morbidity, with two thirds of children being in alternative care for child protection reasons - a direct or indirect result of maternal drug misuse. Largely due to the successful recruiting and training of carers in the Lothian region, the child's HIV status was not a significant determinant of whether the child was in care. The policy of caring for children within home environments has also meant that no child was placed in an institution. ${ }^{21}$

The needs of grandparents as carers of young children have not been well met, although HIV is recognised as a family illness which may affect many generations and result in grandparents mourning the loss of their children while struggling to cope with the demands of grandchildren affected by loss of parents. The situation is likely to worsen, as Edinburgh approaches the 15th year of its HIV epidemic and more young adults die from AIDS related illnesses. The Scottish Health Service laboratories continue to report new positive HIV antibody test results. Since 1986, there has been a decline in the number of reports among injecting drug users, but there has been an increase in the numbers of individuals infected through heterosexual and homosexual intercourse. On 30 June 1997, there were 2636 people reported with HIV infection in Scotland, of whom 1201 (46\%) live in and around Edinburgh. ${ }^{22}$ Although 32 children ( $27 \%$ of cohort) had lost their mother, many had also lost their father but information regarding paternal health, morbidity, and mortality was difficult to obtain due to unstable family structures.

HIV is known to affect the developmental and cognitive abilities of children. ${ }^{323-25}$ Thus far, studies have concentrated on the educational attainments of infected children only. In our study, $20 \%$ of the school aged children had a special educational need, defined as a problem requiring extra resources. Like previous studies, we found that infected children required additional educational support mainly because of learning difficulties and ill health caused by HIV. ${ }^{23}{ }^{24}$ In contrast, uninfected children had problems at school which were related to disruptive and challenging behaviour, with three of 86 children (3.5\%) educated outside of mainstream facilities. This is almost twice the national figure of $2.1 \%$ for all children in the UK who had disabling emotional and behavioural problems. ${ }^{26}$ Often, the educational authorities, when excluding children from school or placing them in special schools, were not aware of HIV in the family. As increasing numbers of children with disabilities attend mainstream schools with additional support, our finding of one in five children with documented special educational needs is likely to be an underestimate of the problem. No legal duty has been imposed on health authorities to detect children with special needs, and the stigma of HIV will deter many families from seeking help. Our experience is that a health concern, usually trivial, is the excuse for many families to re-establish contact. Even so, parents resist attempts from health care professionals at making referrals for counselling or support for the child.

Our finding that the majority of children were unaware of their parent's diagnosis is understandable but worrying. An American study showed that only half of parents with HIV infection reported that their children older than 4 years knew of the parent's diagnosis, while two thirds of the parents did not perceive that their children needed any support or counselling regarding parental illness. ${ }^{27}$ Previous authors have documented the stress, pain, and sense of failure experienced by women which prevent them from discussing their HIV status with their children. ${ }^{8}{ }^{28}$ Unlike most other chronic childhood illnesses, HIV infection still carries a heavy burden of stigma and secrecy, especially surrounding parental diagnosis and the risk activities involved. In families which have experienced multiple deaths, children are left with carers who are unprepared to address the many issues arising from the deaths of several family members from undisclosed diagnoses. The Children Act $1989^{12}$ and the Children (Scotland) Act $1995^{13}$ promote parental responsibilities rather than rights, but agencies dealing with adult drug abuse and HIV defend the parents' rights to confidentiality. It is important to acknowledge the need for families to find their own time and space to involve the children, but the rights of children to be involved in decisions which affect them must not be ignored. ${ }^{29}$ There is also an urgency for parents to inform their children of future plans before the onset of a crisis precipitated by advanced disease, or AIDS dementia, both of which will render parents incapable of being part of the planning process.

For the entire cohort, the majority of families (72\%) appeared to be receiving some form of support, either on a voluntary or statutory basis. Where there was an infected child, $88 \%$ of the families were in contact with some service. Compared with the figure from a previous population survey which revealed that $62 \%$ of families with disabled children belonged to a voluntary organisation, ${ }^{26}$ the families with an infected child would seem to be better supported. The support, however, was largely from statutory agencies for child protection reasons.

On a global basis, increasing numbers of women have been infected with HIV. Although transmission of the virus from mother to child can be reduced by the use of antiretroviral treatment, this intervention is beyond the financial resources of many countries in the developing world, and will not eliminate the 
numbers of children affected by maternal illness. This study has highlighted the multiple needs of children born to women with HIV infection. Whether the children are infected or uninfected, they are clearly profoundly affected by HIV in the family. There will continue to be a growing demand for counselling and support services to prepare these children and young people for alternative care and bereavement. Special educational provisions will also be required. In the current political and economic climate, these responsibilities are shelved as health care and educational and social services authorities struggle to cope with increasing demands on diminishing budgets. If official statistics concentrate only on the numbers of infected children, the needs of the majority of children born to women infected with HIV will be overlooked.

This study was supported by grants from the AIDS Virus Education Research Trust (AVERT), and the Medical Research Council (SPG9810211). We thank Alan Wilson and Sarah Povey for their help with analysis of the maternal database, and Rob Elton for statistical advice.

1 European Collaborative Study. Natural history of verticallyacquired human immunodeficiency virus-1 infection. Pediatrics 1994;94:815-9.

2 Tovo PA, DeMartino M, Gabiano C, et al. Prognostic Tovo PA, DeMartino M, Gabiano C, et al. Prognostic factors and survival in children

3 Grubman S, Gross E, Lerner-Weiss N, et al. Older children and adolescents living with perinatally-acquired human immunodeficiency virus infection. Pediatrics 1995;95:657 63.

4 Sharland M, Gibb D, Tudor-Williams G, Walters S, Novelli V. Paediatric HIV infection. Arch Dis Child 1997;76 293-96.

5 Pinching AJ. Managing HIV disease after Delta. BMf 1995; 312:521-52.

6 British HIV Association guidelines for antiretroviral treatment of HIV seropositive individuals. Lancet 1997;349. 1086-92

7 Connor EM, Sperling RS, Gelber R, et al. Reduction of maternal-infant transmission of human immunodeficiency virus type 1 with zidovudine treatment. $N$ Engl $f \mathrm{Med}$ 1994;331:1 173-80.

8 Melvin D, Sherr L. The child in the family-responding to AIDS and HIV. AIDS Care 1993;5:35-42.

9 Levine C. Orphans of the HIV epidemic: unmet needs in six Levine C. Orphans of the HIV epidemic:

10 Imrie J, Coombes Y. No time to waste: the scale and dimension of the problem of children affected by HIVIAIDS in the United Kingdom. Essex: Barnardos, 1995.
11 European Collaborative Study. Social care of children born to HIV-infected mothers in Europe. AIDS Care 1998 (in press).

12 Department of Health. An introduction to the Children Act. London: HMSO, 1989.

13 The Scottish Office Social Work Services Group. The Children (Scotland) Act 1995. Regulations and guidance. Volume 1. Support and protection for children and their families. Edinburgh: HMSO, 1997.

14 Ronald PJ, Robertson JR, Duncan B, Thomson A. Children of parents infected with HIV in Lothian. BMF 1993;306: 649-50.

15 Inglis S, Morton S. Children affected by HIV and AIDS in Scotland. Edinburgh: Children in Scotland, 1996.

16 Mok JYQ, Hague RA, Yap PL, et al. Vertical transmission of HIV: a prospective study. Arch Dis Child 1989;64:1140-5.

17 Centers for Disease Control and Prevention. 1994 Revised classification for human immunodeficiency virus infection in children less than 13 years of age. $M M W R$ 1994;12:110 .

18 Centers for Disease Control. Revision of the CDC surveillance case-definition for acquired immunodeficiency syndrome. MMWR 1987;36(suppl 1S):3-15.

19 Mok JYQ, Mitchell FM. Communicating with parents and children about medical and nursing procedures. In: Morton S, Johnson D, eds. Children and HIV. Supporting children and their families. Edinburgh: Children in Scotland, Stationery Office, 1996:49-57.

20 Mok JYQ, Ross A, Raab G, Hamilton B, Gilkison S, Johnstone FD. Maternal HIV and drug use: effect on health and social morbidity. Arch Dis Child 1996;74:210-4.

21 Mok J, O'Hara G. Placement of children from HIV-affected families: the Edinburgh experience. Pediatric AIDS and HIV Infection 1990;1:20-2.

22 Scottish Centre for Infection and Environmental Health (SCIEH). AIDS News Supplement to the Weekly Report (ANSWER) 1997:7.

23 Papola P, Alvarez M, Cohen HJ. Developmental and service needs of school-age children with human immunodeficiency virus infection: a descriptive study. Pediatrics 1994;94:914-8

24 Tardieu M, Mayaux MJ, Seibel N, et al. Cognitive assessment of school-age children infected with maternally transmitted human immunodeficiency virus type $1 . \mathcal{J}$ Pediatr 1995;126:375-9.

25 Lobato MN, Caldwell MB, Ng P, Oxtoby MJ, and the Pediatric Spectrum of Disease Clinical Consortium. Encephalopathy in children with perinatally acquired human immunodeficiency virus infection. F Pediatr 1995;126:7105.

26 Office of Population Censuses and Surveys. Report 6. Disabled children: services, transport and education. London: HMSO, 1989.

27 Niebuhr V, Hughes J, Pollard R. Parents with human immunodeficiency virus infection: perceptions of their children's emotional needs. Pediatrics 1994;93:421-6.

28 Semple SJ, Patterson TL, Temoshok LR. Identification of psychobiological stressors among HIV-positive women. Women and Health 1993;20:15-36.

29 United Nations. Convention on the rights of the child 1989. Geneva: UN, 1989. 